\title{
Selection and Implementation of ERP Systems: A Comparison of SAP implementation between BIH and Turkey
}

Seyda Findik, Ali Osman Kusakci, Fehim Findik, Sumeyye Kusakci *

Abstract:

In this research, the selection and implementation of ERP Systems will be discussed. The ERP concept, the selection process, and the importance of selecting a certain ERP solution for the companies will also be dealt with. However, implementation of ERP software brings not only benefits, but also incurs costs. After the literature review of ERP implementation strategies, a survey is reviewed that was conducted among several large and mid-size companies that adopted SAP, one of the major ERP solutions, in their businesses in Bosnia and Herzegovina and Turkey. The focus of the survey will be on different aspects of SAP implementation, such as struggles that have been faced during its implementation and its benefits following implementation. In the final section, a comparison is made between Turkish and Bosnian companies. While the study indicates some differences in implementation strategies and major benefits, similarities between the two countries are more pronounced.

Key words: ERP, Enterprise Resource Planning, ERP selection, ERP implementation, SAP

JEL: M10, M15, O32, O33

DOI: $10.2478 / v 10033-012-0002-x$

\section{Introduction}

In this current information age, the automation of service and production systems is an inevitable process. One of the main pillars of the automation process in business is so-called Enterprise Resource Planning systems. Hirt \& Swanson (1999) defines ERP software as a management information tool designed to model and automate many of the basic processes of a company, from finance to the shop floor, with the goal of integrating information across the company and eliminating complex, expensive links between computer systems that were never meant to communicate.

ERP systems are also enterprise-wide software systems which integrate processes impeccably throughout several functional areas and also across geographical locations. By using a common database for data storage, ERP Systems are able to provide developed workflow, access to real-time information, and adjustments which make business practices more convenient (Parkhill, et. al. 2010).
ERP also solves fragmentation of information in large

* Seyda Findik

MBA Student at Istanbul Fatih University, Turkey

Ali Osman Kusakci

Faculty of Engineering and Natural Sciences, International University of Sarajevo, Bosnia and Herzegovina

* Seyda Findik

Faculty of Engineering and Natural Sciences, International University of Sarajevo, Bosnia and Herzegovina

* Seyda Findik

Faculty of Engineering and Natural Sciences, International University of Sarajevo, Bosnia and Herzegovina 
business organizations (Themistocleous, et. al. 2001). ERP systems create an environment which allows creativity, innovation, and the expansion of individual awareness.

With the help of ERP, the best practices can easily be confirmed, and companies can standardize business processes, and focus their efforts on serving their customers, therefore maximizing profits for the organization (Laframboise \& Reye, 2005). ERP systems create an environment which allows creativity, innovation, and the expansion of individual awareness. Sixty-three percent of large ERP customers have acknowledged that ERP implementation brings benefits and success (Maguire, et. al. 2010).

Since the early 1990s, the ERP software market has been and continues to be one of the fastest growing segments of the information technology (IT) industry, with growth rates averaging from 30\% to $40 \%$ per year. ERP packaged software purchases are very expensive disbursements for companies, with costs equalling hundreds of thousands, even millions of dollars. While these IT expenditures represent a significant portion of capital expenditures for many organizations and will continue to increase even more, little is known about how these expenditures are made, and what stages organizations have to go through when they buy ERP software (Verville \& Halingten, 2003).

There are dozens of vendors of ERP systems. However, the top five ERP system vendors are SAP, PeopleSoft, Oracle, J.D. Edwards, and Baan. SAP has been recognized as the leader with more than 50 percent of the market. This paper focuses on SAP implementation as a leading example of ERP system implementation both in Turkey and Bosnia and Herzegovina. The remaining portion of this paper is organized as follows: the overall ERP concept, the ERP selection process and the importance of selecting the right ERP software will be examined. After explaining the selection process, ERP implementation strategies and the advantages and drawbacks of ERP implementation will be touched upon. The key subject of the thesis is SAP implementation in both Turkish and BIH companies. The survey was conducted in twenty-eight companies both in Turkey and Bosnia. The final part of the paper deals with the results of the survey, a comparison between the two countries, and a discussion of the results.

\section{ERP Selection Process}

In this section, the importance of selecting the correct ERP system and different selection methods will be presented. The choice of the right ERP system and selection process are of considerable importance because of the fact that it depends upon a certain level of process adaptation and affects corporate culture and work organization (Verville \& Halingten, 2003). ERP selection processes are complex, demanding, intensive, and timeconsuming (Verville \& Halingten, 2003), and failures in ERP implementation have been linked to the selection of ineffective, and inappropriate ERP systems (Bakås, et. al. 2007)

To demonstrate the importance making the right selection, Stefanou (2001) states that the cost of making a decision regarding the acquisition of ERP software can account for as much as 30 percent of the overall cost of the investment and that the ERP selection process can use up to 20 employees for 14 months. Stefanou (2001) proposes two approaches for ERP selection, financial and non-financial. Traditionally, the evaluation and selection of IS (Information System) investments were generally based on financial criteria. Financial measures, including Net Present Value (NPV), Internal Rate of Return (IRR), and Return on Investment (ROI) were employed only to show, most of the time, the validity of the so-called 'IT productivity paradox'. Although it is important to comprehend the financial measures, they are not the only concerns, nor are they sufficient to support the justification of ERP systems justification for the following reasons:

- A large number of ERP benefits and costs are not easily identifiable, as they span the entire life-cycle of an ERP project.

- Costs and benefits, even when they are identified, are not easily quantifiable, as has been already recognized to be generally the case with IT investments

- Major benefits (and costs) do not emerge from the use of ERP software per se but rather from the organizational change induced by ERP and the extendibility of the software to support additional functionality (Stefanou, 2001).

Apart from financial measures, the non-financial measures are to be taken into account to provide a complete picture of the potential and costs of ERP projects. The complexity of IT projects and customer service should be recognized as a considerable barrier to 
effective evaluation. Furthermore, the decision makers' instincts, their ways of understanding and perceptions of the problem, as well as their ways of thinking and interpreting information may be an accurate factor in ERP selection and the implementation success (Stefanou, 2001).

Moreover, Bernroider \& Koch (2000) identify 29 ERP selection criteria by applying the Delphi Method to a combination of 138 organizations comprised of 22 small or medium size companies and 116 large companies.

Illa, et al. (2000) develop, apply and propose SHERPA (Systematic Help for ERP Acquisitions), which is a very accurate and reliable methodology tailored for small and medium companies, for which other sophisticated methods are difficult to apply. The method covers the entirety of the ERP acquisition process, but does not cover the implementation of the selected ERP, its usage, maintenance, evolution or retirement.

\section{ERP implementation}

Themistocleous \& Watson (2005) note that although there have been countless ERP implementation efforts during the past fifteen years, "many companies still have significant functions and resources that are not under the broad ERP umbrella". Maguire, et al. (2010) states that the comprehensive use of ERP reflects the need for businesses and organizations to replace older software systems and achieve integration of different organizational functions and processes. To integrate all departments of an organization, implementation of ERP is beginning to be considered inevitable by companies. "For many organizations, implementing ERP means moving from a confederation of loosely coupled systems to a tightly coupled one" (Yeh \& OuYang, 2010).

Hakim \& Hakim (2010) mentions the three most widely used and discussed ERP implementation strategies: Big Bang Theory, Phased Rollout, and Parallel Adoption. In Big Bang Theory, implementation happens in a single instance, and all users move to the new system on a specific date, with the appeal that it concentrates on the organization for a shorter period of time. The disadvantages of big bang implementation is that it is often rushed, details are mostly ignored, is riskier, and because of its intensive nature, the pain is often more severe. The other implementation strategy is the phased rollout approach. It allows project teams to take their time in the planning, customization, and testing of the system while continuing with their day-to-day jobs. The disadvantages of this approach is that it might lead to "change fatigue," which can affect employees negatively through constant change. Since projects take longer periods than the big bang theory, it could be draining to employees (Kimberling, 2006). Parallel Adoption is another ERP implementation strategy, and is one of the least risky, as it includes running the old and new ERP systems together (Patrick, 2011).

Furthermore, according to Parr \& Shanks (2000), there are three implementation approaches: comprehensive, middle-road, and vanilla. The comprehensive approach represents the most ambitious implementation approach. Typically it involves a multi-national company that decides to implement an ERP in multiple sites, often across national boundaries. The middle-road category is mid-way between a comprehensive and a vanilla implementation. Characteristically, there are multiple sites and a major decision is to implement a selection of only core ERP modules. Finally, the vanilla approach is the least ambitious and the least risky. Typically, the implementation is on one site only, and the number of prospective system users is small.

The implementation stage is a very crucial factor for an ERP adoption process. As stated by Doom et.al. (2010), 70 percent of companies implementing ERP in the USA consider the project successful. More than 55 percent of companies admit that the planned budget was exceeded, on average by 60.6 per cent. When these budget overflows are counted as failures, the success rate of ERP implementation is less than 50 percent. Another rate of success is given by Meta Group, which reports a 30\% success rate in ERP implementation projects (Nair, et. al. 2010). Additionally, the business research firm Standish Group found that only 10 percent of ERP implementation projects are completed as planned, on time, and within budget. Fifty-five percent are completed late or over budget, and the other 35 percent of projects are canceled because of difficulties.

\subsection{Benefits of ERP implementation}

Shang \& Seddony (2000) note that there are five dimensions of ERP benefits: operational, managerial, strategic, IT infrastructure, and organizational. Some of the important sub-dimensions are cost reduction, cycle time reduction, productivity improvement, quality improvement, customer services improvement, performance improvement, building of external linkages, 
IT cost reduction, and empowerment. Table 1 shows these benefits of ERP implementation.

A survey held of companies in Bahrain found a number of benefits according to interviewees' opinions and the degree to which these benefits have been realized after implementation. The results of the survey indicated that ERP systems offer substantial benefits. Out of the 27 mentioned benefits, improving productivity was perceived by interviewees as the prime benefit, while optimizing inventory was considered the second most beneficial factor. The least beneficial factor according to the survey was reducing the number of employees (Kamhawi, 2008).

\subsection{The Drawbacks of ERP implementation}

It is inevitable that the full implementation of ERP software carries with it some subsequent problems and drawbacks. It has been estimated that about half of ERP implementations fail to meet expectations for some reason (Stefanou, 2001) and it is estimated that at least 90\% of ERP implementations end up late or over budget (Gibson, et. al. 1999). Due to their complexity, ERP systems are difficult to implement, as well as to carry on with and maintain. Their implementation can be very expensive and extremely time consuming and there is no guarantee that it will be a success. For instance, at Hewlett-Packard, a $\$ 400$ million loss in the third quarter of 2004 was blamed on poorly managed migration to a new ERP system $(\mathrm{Oz}, 2009)$. As an additional example, out of 100 firms investigated, Davenport (2000) found that only ten derived any real value from implementing an ERP system (Tsamantanis \& Kogetsidis, 2006).

According to (Jorney, n.d.), the main drawbacks can be classified into five main issues, which are cost, time, efficiency, customization, and data integration.

- Cost: ERP solutions are very expensive and may also require additional acquisitions or modifications during training sessions, so the implementation costs can rise considerably.

- Time: The implementation requires a tremendous time commitment from a company's information technology department or outside professionals. Furthermore, training employees to efficiently and effectively use the ERP system can be very time consuming.

- Efficiency: Even though an ERP system should improve efficiency if implemented and used correctly, the adoption period may cause inefficient business flow.

- Customization: ERP systems are either not very customizable, or customization involves a lot of time and money.

- Data Integration: To integrate an ERP system with other software might require that the software be modified.

As a result the drawbacks and barriers of ERP Implementation should not be disregarded. In order to be successful in implementing ERP systems in companies, they should be examined deeply in order to turn these drawbacks into benefits.

The human- and organizational-change aspects, and the resistance to these changes, are also an essential factor of success. Hence some researchers argue that social factors, more than technical or economic factors, are critical to the success of ERP projects. According to Yeh \& OuYang (2010), the main drawback faced by all of the companies has been resistance to change. Either employees are often reluctant to learn new techniques or the information technology (IT) department is reluctant to change because of the department's attachment to existing software.

Implementation of ERP systems can fail because of some external challenges: the space between system capabilities and business needs, lack of expertise on the consultant's part, and mismanagement of the implementation project.

\section{Data Set and Methodology}

The data used in this study was obtained in a survey investigating SAP implementation, benefits, and the drawbacks of implementation in both BIH and Turkish companies. After creating a draft survey, the survey was sent to a SAP Consultant to be checked and developed. After some relevant changes in the survey, the survey was shared with companies. The survey was conducted during the spring of 2011. For the purposes of this study, the data was acquired through multiple questions. The survey consists of fifteen questions. Nineteen adequate answers from Turkey and nine answers from BIH have been provided through an online survey.

The present study has certain limitations that should be taken into account. The most significant impediment in this study is that the test was not adapted according to the cultures of the participants, and none of the 


\begin{tabular}{|c|c|c|}
\hline & BIH & TR \\
\hline \multicolumn{3}{|c|}{ Q1: Which products of SAP has your company been using? } \\
\hline $\mathrm{SAP} R / 3$ & 7 & 17 \\
\hline SAP Business One & 2 & 2 \\
\hline \multicolumn{3}{|c|}{ Q2. Have you done implementation in your entire Company? } \\
\hline Yes & 5 & 16 \\
\hline No & 4 & 3 \\
\hline \multicolumn{3}{|c|}{ Q3. When did your organization purchase the software? } \\
\hline Pre-2005 & 3 & 4 \\
\hline 2006-2007 & 1 & 6 \\
\hline 2008-2009 & 4 & 7 \\
\hline 2010 & 1 & 2 \\
\hline \multicolumn{3}{|c|}{ Q4. What is the size of your company? } \\
\hline Small & 4 & 7 \\
\hline Medium & 0 & 3 \\
\hline Large & 5 & 9 \\
\hline
\end{tabular}

Table 1: Answers of first four questions related to general data about surveyed companies

\begin{tabular}{|c|c|c|}
\hline & BIH & TR \\
\hline \multicolumn{3}{|c|}{ Q5: Do you find it costly and time consuming to modify SAP to adapt to changes in your business process? } \\
\hline Yes & 3 & 6 \\
\hline No & 1 & 6 \\
\hline Partially & 3 & 7 \\
\hline \multicolumn{3}{|c|}{ Q6. How would you rate the difficulty of the process change and organizational change aspects of your SAP system? } \\
\hline Very easy & 0 & 2 \\
\hline Easy & 1 & 3 \\
\hline Difficult & 6 & 12 \\
\hline Very difficult & 1 & 1 \\
\hline No idea & 1 & 1 \\
\hline \multicolumn{3}{|c|}{ Q7. Overall, how would you rate the difficulty of the technical aspects of your SAP implementation? } \\
\hline Very easy & 0 & 2 \\
\hline Easy & 2 & 3 \\
\hline Difficult & 5 & 11 \\
\hline Very difficult & 1 & 2 \\
\hline No idea & 1 & 1 \\
\hline \multicolumn{3}{|c|}{ Q8. What issues have you faced during SAP implementation? } \\
\hline Delay & 3 & 8 \\
\hline Lack of satisfaction in terms of requirements & 0 & 4 \\
\hline Lack of satisfaction in terms of objectives & 0 & 0 \\
\hline None & 2 & 4 \\
\hline Other & 4 & 3 \\
\hline \multicolumn{3}{|c|}{$\begin{array}{l}\text { Q9. How long was it before business users were able to independently perform tasks such as report and workflow } \\
\text { wizards? }\end{array}$} \\
\hline Less than 6 months & 5 & 6 \\
\hline 6 months to 1 year & 1 & 6 \\
\hline 1 year + & 3 & 7 \\
\hline
\end{tabular}

Table 2: Answers for second part related to implementation phase

participants were native English speakers. The study could have been adapted to the language of the questionnaire by using forward and back-translation methods, such that the potential for misinterpretation could have been minimized. Another major drawback of this study is that the number of responses was not sufficient: 19 responses were received from Turkish participants, while the number of responses obtained 
from Bosnian participants was 9. This highly unbalanced dataset is partially due to the highly different scales of the abovementioned economies.

\section{Results}

The data is analyzed using a t-test and a chi-square test through the statistical package for social sciences (SPSS). The t-test was used to make a comparison of the means of the two independent samples and identify whether the means of the two groups are statistically different from each other.

$$
t=\frac{\bar{x}_{1}-\bar{x}_{2}}{\sqrt{\frac{\operatorname{var}_{1}}{n_{1}}+\frac{\operatorname{var}_{2}}{n_{2}}}}
$$

Another test used throughout this study is the chisquare test to determine whether there is a significant difference between the expected frequencies and the observed frequencies in one or more categories.

$$
\begin{gathered}
X^{2}=\sum \frac{(\text { Observed Freq. }- \text { Expected Freq. })^{2}}{\text { Expected Freq. }}= \\
\sum \frac{\left(F_{o}-F_{e}\right)^{2}}{F_{e}}
\end{gathered}
$$

The survey contains 15 questions aiming at different aspects of SAP implementation strategies. The first four questions relate to common statistics. The results are given in Table 1.

The second part of the survey questions possible issues, problems and difficulties during the implementation phase of SAP software. This part contains five questions, and the results are illustrated in Table 2 .

To compare both samples the following four hypothe proposed and tested.

- H1:There is no significant difference between both samples to question 5 .

- H2: There is no significant difference in question 6 between BIH and Turkish SAP users.

- H3: There is no significant difference in question 7 between BIH and Turkish SAP users.

- H4: There is no significant difference between both samples to question 8 .
H1: There is no significant difference between both samples to question 5 .

\begin{tabular}{|l|l|}
\hline \multicolumn{2}{|l|}{ Results } \\
\hline Critical Value & 5.9915 \\
\hline Chi-Square Test Statistic & 1.5283 \\
\hline$p$-Value & 0.4657 \\
\hline Do not reject the null hypothesis & \\
\hline
\end{tabular}

Table 3: Chi-square test statistics for $\mathrm{H} 1$

In the first hypothesis, the critical value is 5.9915 at the 5\% significance level. The Chi-square value was 1.5283 . Therefore, there is no significant difference between the two groups. The amount of difference between the expected and actual data is likely just due to chance. Thus, the hypothesis may not be disregarded.

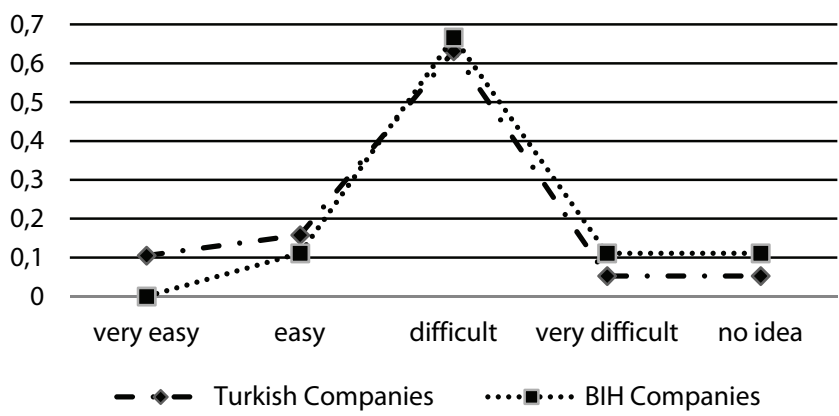

Figure 1: Answers to the sixth question

Figure 1 demonstrates the percentages for the sixth question. The percentages are $11 \%$ for easy, $67 \%$ for difficult, $11 \%$ for very difficult and $11 \%$ for don't know for the Bosnian participants and $11 \%$ for very easy, $16 \%$ for easy, $63 \%$ for difficult, $5 \%$ for very difficult and $5 \%$ for don't know for the Turkish participants.

\begin{tabular}{|l|l|c|c|c|c|}
\hline & & $\mathrm{N}$ & Mean & $\begin{array}{c}\text { Std. } \\
\text { Deviation }\end{array}$ & $\begin{array}{c}\text { Std. Error } \\
\text { Mean }\end{array}$ \\
\hline \multirow{2}{*}{ Q6 } & Bosnian & 9 & 3.78 & .833 & .278 \\
\cline { 2 - 6 } & Turkish & 19 & 3.37 & 1.165 & .267 \\
\hline \multirow{2}{*}{ Q7 } & Bosnian & 9 & 3.56 & 1.014 & .338 \\
\cline { 2 - 6 } & Turkish & 19 & 3.42 & 1.216 & .279 \\
\hline
\end{tabular}

Table 4: Descriptive statistics for questions 6 and 7

H2: There is no significant difference in question 6 between BIH and Turkish SAP users.

The t-test for the second hypothesis was not significant ( $M=3.575 ; \mathrm{sd}=0.999 \mathrm{t}=0.942$ : $d f=26 ; \mathrm{p}>0.05)$. $(M=35.012445, S D=5.605)$. Based on the statistical data 


\begin{tabular}{|c|c|c|c|c|c|c|c|c|c|c|}
\hline & & \multicolumn{2}{|c|}{$\begin{array}{l}\text { Levene's Test } \\
\text { for Equality of } \\
\text { Variances }\end{array}$} & & \multicolumn{4}{|c|}{ t-test for Equality of Means } & \multicolumn{2}{|c|}{$\begin{array}{l}\text { 95\% Confidence } \\
\text { Interval of the } \\
\text { Difference }\end{array}$} \\
\hline & & $\mathrm{F}$ & Sig. & $\mathrm{t}$ & $\mathrm{df}$ & $\begin{array}{l}\text { Sig. }(2- \\
\text { tailed) }\end{array}$ & $\begin{array}{c}\text { Mean } \\
\text { Difference }\end{array}$ & $\begin{array}{l}\text { Std. Error } \\
\text { Difference }\end{array}$ & Lower & Upper \\
\hline \multirow[t]{2}{*}{ Q6 } & * & 2.780 & .107 & .942 & 26 & .355 & .409 & .434 & -.484 & 1.302 \\
\hline & ** & & & 1.062 & 21.482 & .300 & .409 & .385 & -.391 & 1.210 \\
\hline \multirow[t]{2}{*}{ Q7 } & $*$ & .574 & .455 & .287 & 26 & .776 & .135 & .469 & -.829 & 1.098 \\
\hline & ** & & & .307 & 18.754 & .762 & .135 & .438 & -.784 & 1.053 \\
\hline \multicolumn{11}{|c|}{$\begin{array}{l}\text { * equal variances are assumed } \\
\text { * equal variances are not assume }\end{array}$} \\
\hline
\end{tabular}

Table 5: Independent Samples Test for Questions 6 and 7

given in Table 4 and Table 5 there is no statistically significant evidence to reject the second $\left(\mathrm{H}_{2}\right)$ (hypothesis which assumes that there is no significant difference in question 6 between Bosnian and Turkish SAP users.

H3: There is no significant difference in question 7 between BIH and Turkish SAP users.

The t-test for the third hypothesis was not significant $(M=3.49 ; s d=1.115 t=.287$ : $d f=26 ; p>0.05)$. Based on the statistical data given in Table 4 and Table 5 there is no statistically significant evidence to reject the third $\left(\mathrm{H}_{3}\right)$ (hypothesis, which assumes that there is no significant difference in question 7 between BIH and Turkish SAP users.

H4: There is no significant difference between the two samples to question 8 .

\begin{tabular}{|l|r|}
\hline Results \\
\hline Critical Value & 7.8147 \\
\hline Chi-Square Test Statistic & 11.4402 \\
\hline$p$-Value & 0.0096 \\
\hline Reject the null hypothesis & \\
\hline
\end{tabular}

Table 6: Chi-square test statistics for $\mathrm{H} 4$

In the fourth hypothesis, the critical value is 7.8147 at the $5 \%$ significance level. The Chi-square value was 11.4402, which is greater than 7.8147. There is a significant difference between the groups we are studying. The amount of difference between expected and actual data is not likely just due to chance. Thus, we conclude that our sample supports the hypothesis of a difference.

The third part of the survey contains questions aiming to study the after-implementation phase of SAP software and discuss the results of the implementation. This part contains five questions, while the results are illustrated in Table 7.

\begin{tabular}{lll}
\multicolumn{1}{c}{ BIH } & TR \\
\hline Q10: Do you find SAP easy and intuitive to use? \\
\hline Yes & 6 & 10 \\
No & 0 & 1 \\
Partially & 3 & 8 \\
\hline Q11. Was the implementation a success? & \\
\hline Yes & 9 & 18 \\
No & 0 & 1 \\
\hline
\end{tabular}

Q12. Are you satisfied with your implementation of SAP?

$\begin{array}{lll}\text { Very satisfied } & 3 & 5 \\ \text { Satisfied } & 6 & 10 \\ \text { Neutral } & 0 & 3 \\ \text { Dissatisfied } & 0 & 0 \\ \text { Very dissatisfied } & 0 & 1\end{array}$

Q13. Do you feel a positive difference in your everyday business between before and after SAP implementation?

\begin{tabular}{lll} 
Yes & 9 & 17 \\
No & 0 & 2 \\
\hline
\end{tabular}

Q14. Please choose the benefits of implementing SAP in your company.

Better integration of business processes $\quad 6 \quad 6$

Saving time and efforts in employees' activ $0 \quad 3$

$\begin{array}{lll}\text { Transparent and on-time reports } & 0 & 4\end{array}$

Better control of business processes $\quad 3 \quad 6$

Table 7: Answers for third part related to after-implementation phase

To compare both samples the following four hypotheses are proposed and tested.

- H5: There is no significant difference between both samples to question 10 .

- H6: There is no significant difference in question 12 between BIH and Turkish SAP users.

- H7: There is no significant difference in question 14 between BIH and Turkish SAP users. 


\begin{tabular}{|l|l|}
\hline Results & 5.9915 \\
\hline Critical Value & 0.8038 \\
\hline Chi-Square Test Statistic & 0.6690 \\
\hline$p$-Value & \\
\hline Do not reject the null hypothesis & \\
\hline
\end{tabular}

Table 8: Chi-square test statistics for $\mathrm{H} 5$

\begin{tabular}{|l|l|c|c|c|c|}
\hline & & $\mathrm{N}$ & Mean & Std. Deviation & Std. Error Mean \\
\hline \multirow{2}{*}{ Q12 } & Bosnian & 9 & 4.33 & .500 & .167 \\
\cline { 2 - 6 } & Turkish & 19 & 3.95 & .970 & .223 \\
\hline
\end{tabular}

Table 9: Descriptive statistics for questions 12

\begin{tabular}{|c|c|c|c|c|c|c|c|c|c|c|}
\hline & & \multicolumn{2}{|c|}{$\begin{array}{l}\text { Levene's Test } \\
\text { for Equality of } \\
\text { Variances }\end{array}$} & \multicolumn{5}{|c|}{ t-test for Equality of Means } & \multicolumn{2}{|c|}{$\begin{array}{l}95 \% \text { Confidence } \\
\text { Interval of the } \\
\text { Difference }\end{array}$} \\
\hline & & $F$ & Sig. & $t$ & $d f$ & $\begin{array}{l}\text { Sig. (2- } \\
\text { tailed) }\end{array}$ & $\begin{array}{c}\text { Mean } \\
\text { Difference }\end{array}$ & $\begin{array}{c}\text { Std. Error } \\
\text { Difference }\end{array}$ & Lower & Upper \\
\hline \multirow[t]{2}{*}{ Q12 } & * & .427 & .519 & 1.117 & 26 & .274 & .386 & .345 & -.324 & 1.096 \\
\hline & ** & & & 1.388 & 25.680 & .177 & .386 & .278 & -.186 & .958 \\
\hline
\end{tabular}

Table 10: Independent Samples Test for Questions 12

\begin{tabular}{|l|l|}
\hline Results & 7.8147 \\
\hline Critical Value & 3.1813 \\
\hline Chi-Square Test Statistic & 0.3645 \\
\hline$p$-Value & \\
\hline Do not reject the null hypothesis & \\
\hline
\end{tabular}

Table 11: Chi-square test statistics for $\mathrm{H} 7$

H5: There is no significant difference between both samples to question 10 .

In the fifth hypothesis, the critical value is 5.9915 at the $5 \%$ significance level. As indicated in Table 8 , the Chisquare value obtained is 0.8038 , which is less than the critical value. There is no significant difference between the two groups. The amount of difference between the expected and actual data is likely just due to chance. Thus, it can be concluded that the sample does not support the hypothesis of a difference.

H6: There is no significant difference in question 12 between BIH and Turkish SAP users.

As given in Table 9 and Table 10, the t-test for the sixth hypothesis was not significant $(M=4.14 ; s d=0.735$ $t=1.117$ : $d f=26 ; p>0.05$ ). There is no statistically significant evidence to reject the sixth $\left(\mathrm{H}_{6}\right)$ hypothesis which assumes that there is no significant difference in question 11 between Bosnian and Turkish SAP users.
H7: There is no significant difference between both samples to question 14 .

In the seventh hypothesis, the critical value is 7.8147 at the $5 \%$ significance level. The Chi-square value was 3.1813, which is less than 7.8147. There is no significant difference between the groups we are studying. The amount of difference between expected and actual data is likely just due to chance. Thus, we conclude that our sample does not support the hypothesis of a difference.

\subsection{Discussion}

The results of the survey reveal some differences in SAP implementation between Bosnian and Turkish Companies.

The results of the first question suggest that both in $\mathrm{BIH}$ and Turkey mostly SAP R/3 is being used. Considering the fourth question about companies' sizes, in $\mathrm{BIH}$, out of 
nine, five are large, and four small sized companies, and in Turkey, out of nineteen, nine are large, three medium, and seven small sized companies. This indicates that regardless of the size of the companies, SAP R/3 is being used both in BIH and Turkey.

Question 2 gives a good representative point about the implementation extent in companies. Fifty-six percent of the Bosnian companies implemented SAP throughout their entire company, while $84 \%$ of the Turkish companies implemented SAP throughout their entire company. Taking into consideration the economic development of two countries and the costly implementation of SAP, this significant difference is likely to occur.

The chi-square result of the tenth question suggests that notions and perceptions about the ease and intuitiveness of using SAP are statistically independent. Given the statistical percentages, namely $67 \%$ yes from $\mathrm{BIH}$, and $53 \%$ yes from Turkey, it can be concluded that SAP usage is convenient and not troublesome.

By looking at the percentages from answers to the ninth question, it can be seen that Bosnian users are more able to independently perform tasks such as report and workflow wizards. While Bosnian SAP users' percentage for less than six months is $56 \%$, the Turkish SAP users' percentage is $31 \%$. This difference may be the result of the differences between Turkish and Bosnian users' inclination to use SAP.

The chi-square test result for the fifth question states that the question and nation are independent. The question asks whether it is costly and time consuming to implement SAP, and both Bosnian and Turkish users generally describe it as partially so. Although the chisquare test indicates that there is no significant difference in terms of nationality for this question, the percentages for Bosnian and Turkish users who chose no were $11 \%$ and $32 \%$, respectively. This statistical data shows that more Turkish SAP users than Bosnians think of SAP implementation as more time consuming and costly. This may be the consequence of the fact that the costs of implementing SAP are higher for Turkish companies.

No significant difference was found regarding questions 6, 7, and 12, showing that Bosnian and Turkish SAP users do not differ in rating the difficulty of the process change and the organizational change aspects of the SAP system, the difficulty of the technical aspects of SAP implementation, and satisfaction with their implementation of the SAP. Since the implementation processes of SAP are the same in both countries, these results are not surprising. Even though there is no significant difference in satisfaction with SAP implementation, Bosnian participants rated higher on satisfied with $67 \%$, compared to $53 \%$ of Turkish participants.

With regard to question 11 concerning implementation success, almost 100\% percent of both Bosnian and Turkish participants answered yes referring to the success of SAP implementation in their company, which could mean that consultancy services were successful in the implementations. There is no difference between nations for this question.

Unlike the other chi-square result, the eighth question suggests that nationality and question 8 are somehow related. Answers yielded the only significant difference between BIH and Turkey. As the question asks about issues faced during implementation, the statistical difference is clear. Whereas $33 \%$ of Bosnian participants chose "delays" as the drawback to SAP implementation, $42 \%$ of Turkish participants chose the same. Although the difference is minor, it could be interpreted in different ways, such as a difference in the availability or amount of consultancy services. Notwithstanding the fact that SAP is new, developing software in $\mathrm{BIH}$, the consultancy services may work well, and perform the implementations in a sufficient way so that there is relatively little tardiness. The huge disproportion in the percentages of responses to "it didn't fulfil your requirements" is another difference between BIH and Turkey. While Bosnian participants' percentage is zero for that question, for Turkish participants it is $21 \%$. This statistical data is also a good confirmation of the case in the first "delay" option.

\section{Conclusion}

After analysis and interpretation of the data some conclusions can be drawn. The results of this study demonstrate that there is only one significant difference among seven hypotheses between Bosnian and Turkish SAP users. Even though no significant difference has been found for seven hypotheses, hypothesis 4 related to the eighth question suggests that that nationality is a factor in that area.

The present study found only one significant relationship between $\mathrm{BIH}$ and Turkey, the underlying reasons for which may be related to the small number of participants from both Turkey and BIH. Since these numbers are nine from $\mathrm{BIH}$ and nineteen from Turkey, the results may not be sufficient. If we could have reached 
more SAP users, we might have obtained different results through comprehensive data. Further research can be directed toward collecting statistically more representative data and extending the questionnaire with additional dimensions such as detailed SAP implementation strategies in both countries. $\mathbf{E}_{\text {. }}$

\section{References}

Hırt, S. G., \& Swanson, E. B. (1999). Journal of Information Technology. Adopting SAP at Siemens Power Corporation, 243-251.

Parkhill, R., Belton, V., Bititci, U., Roberts, A., \& Smith, M. (2010). Using Multiple Criteria Decision Analysis to Aid the Selection of Enterprise Resource Planning Software: A Case Study. Innovation through Knowledge Transfer, 39-49

Themistocleous, M., Irani, Z., \& O'Keefe, R. M. (2001). ERP and Application Integration. Business Process Management Journal, 195204.

Maguire, S., Ojiako, U., \& Said, A. (2010). ERP implementation in Omantel:a case study. Industrial Management \& Data Systems, 78-92.

Laframboise, K., \& Reye, F. (2005). Gaining Competitive Advantage from Integrating Enterprise Resource Planning and Total Quality Management. The Journal of Supply Chain Management , 49-64.

Verville, J., \& Halingten, A. (2003). A six-stage model of the buying process for ERP software. Industrial Marketing Management , 585- 594.

Bakås, O., Romsdal, A., \& Alfnes, E. (2007). Holistic ERP Selection Methodology.

Stefanou, C. (2001). A framework for the ex-ante evaluation of ERP software. European Journal of Information Systems, 204-215.

Bernroider, E., \& Koch, S. (2000). Differences in Characteristics of the ERP System Selection Process between Small or Medium and Large Organizations. Proc. of the Sixth Americas Conference on Information Systems, (pp. 1022-1028). Long Beach, CA.

Illa, X. B., Franch, X., \& Pastor, J. A. (2000). Formalising ERP Selection Criteria. Proceedings of the Tenth International Workshop on Software Specification and Design. Barcelona,Spain.

Themistocleous, M., \& Watson, E. (2005). Editorial: EJIS special issue on making enterprise systems work. European Journal of Information Systems, 107-109.

Yang, C., \& Su, Y.-f. (2009). The Relationship between the Benefits of ERP Systems Imp. and Its Impacts on Firm Performance of SCM. Journal of Enterprise Information Management , 722-752.

Yeh, J. Y., \& OuYang, Y. C. (2010). How an organization changes in ERP implementation: a Taiwan semiconductor case study. Business Process Management Journal , 209-225.

Oz, E. (2009). Management Information System. Boston, Massachusetts: Cengace Course Technology,Thomson.

Davenport, T. H. (2000). Mission Critical: Realizing the Promise of Enterprise Systems. Boston: Harvard Business School Press.

Doom, C., Milis, K., Poelmans, S., \& Bloemen, E. (2010). Critical success factors for ERP Implementations in Belgian SMEs. Journal of Enterprise Information Management, 378-406.

Hakim, A., \& Hakim, H. (2010). A practical model on controlling ERP implementation risks. Journal of Information Systems , 204-214.
Jorney, N. (n.d.). The Disadvantages of ERP. Retrieved March 30 2011, from eHow: http://www.ehow.com/list_6565142_disadvantageserp.html

Kamhawi, E. M. (2008). Enterprise resource-planning systems adoption in Bahrain: motives, benefits, and barriers. Journal of Enterprise Information Management , 310-334.

Kimberling, E. (2006, September 28). ERP's Big Bang Theory. Retrieved May 5, 2011, from toolbox: http://it.toolbox.com/blogs/erproi/erps-big-bang-theory-11954

Parr, A. N., \& Shanks, G. (2000). A Taxonomy of ERP Implementation Approaches. Proceedings of the 33rd Hawaii International Conference on System Sciences. Hawaii: 2000 IEEE.

Shang, S., \& Seddony, P. B. (2000). A Comprehensive Framework for Classifying the Benefits of ERP Systems. Americas Conference on Information Systems (AMCIS) (pp. 1005-1014). Association for Information Systems.

Gibson, N., Holland, C., \& Light, B. (1999). A Case Study of a Fast Track SAP R/3 Implementation at Guilbert. 190-193

Tsamantanis, V., \& Kogetsidis, H. (2006). Implementation of enterprise resource planning systems in the Cypriot brewing industry. British Food Journal , 118-126. 